News

\title{
Classroom coaching: developing constructive internal language
}

Volume I Issue 5 - 2014

\author{
Steven Richfield \\ Clinical Psychologist, Philadelphia, USA
}

\author{
Correspondence: Steven Richfield, Clinical Psychologist, \\ Philadelphia, USA, Tel 610-238-4450, \\ Email director@parentcoachcards.com
}

Received: August 28, 2014 | Published: August 30, 2014

Teachers or counselors might explain that the "thinking voice" helps to solve problems and make good decisions while the "unhelpful voice" can actually make problems worse or lead to bad decisions. An example can make this clear:

Suppose a boy sat down to do his worksheet of ten problems and realized that he could not do three problems on the page. Two thoughts come to mind:

A. "This is impossible; I'll never get a good mark on this. Why even bother trying?"

B. "Well, just because I can't do these three doesn't mean I shouldn't try my best."

"A" can be characterized as the "unhelpful voice" and "B" as the "helpful thinking voice."

Next, children might be presented with the following dichotomy to reinforce their understanding: Examples of the Mind's Two Voices.

\section{In response to academic challenge}

Helpful Thinking Voice

"This looks hard and probably even too hard for me to do... but I'll never know unless I try. I'm going to take it step by step and just forget about how hard it is so I can keep trying."

Unhelpful Voice:

"This looks hard and probably even too hard for me to do...I'm definitely not going to be able to it. I hate this stuff and can't see why we have to learn it."

\section{In response to social challenge}

\section{Helpful Thinking Voice:}

“They don't like me and I don't like the way they are treating me. Maybe I'm different from them and they can't deal with that. Or, maybe they just don't really know me yet, and they'll change their minds when they get to know me better." Unhelpful Voice:’They some of the self-defeating thinking that goes on in children's minds. 
don't like me and I don't like the way they are treating me. They're idiots and I feel like smashing them. If they say one more mean thing to me, I'm definitely going to make them pay for what they're doing to me."

\section{In response to Emotional Challenge}

Helpful Thinking Voice:

“Things didn't work out...again. This is getting really frustrating. It's hard to understand why it's happened to me this time. Maybe somebody else can help me figure it out. Who should I ask?" Unhelpful Voice:

“Things didn't work out...again. Why does this always happen? This is so unfair. I can't believe it. I don't deserve it. Why me?"

Most children will recognize how in each example, the initial thoughts are identical, but the resulting internal dialogue is completely contrary. Discussion then focuses on the imaginary scenarios that might lead to each one of these examples, and the specific phrases that each voice utilizes. In the case of the helpful thinking voice, words and phrases such as "step by step," "maybe" and "hard to understand" are offered to stress the importance of plotting a strategy to cope, making the option of change seem viable, and expressing the quest to make sense out of circumstances. In contrast, words and phrases such as "definitely," "hate," idiots," "feel like smashing them," "always," and "unfair" reveal the emotionally charged and absolute thinking of the unhelpful voice.

The helpful thinking voice examples also demonstrate the attempt to construct solutions to the problems faced by the child in question. In the academic challenge, the child adopts a strategy of minimizing awareness of difficulty. In the social challenge, the child adopts the perception of things changing for the better in the future. In the emotional challenge, the child decides to pursue helpful consultation.

Once children grasp the importance of constructive internal language they will be better able to benefit from the school-based coaching of social and emotional skills. Future articles will address the next steps in that progression.

\section{Acknowledgments}

None.

\section{Conflicts of interest}

Author declares there are non conflicts of interest.

\section{Funding}

None. 